\title{
INITIAL EXPERIENCES IN TREATMENT OF GASTROINTESTINAL FOREIGN BODIES IN CHILDREN
}

\author{
Zlatko Djuric $^{1,2}$, Milan Bojanovic ${ }^{2,3}$, Ivana Budic ${ }^{2,3}$, Jelisaveta Maksimovic ${ }^{2}$ \\ ${ }^{1}$ Pediatric Clinic, Department of Gastroenterology, Clinical Center Niš, Niš, Serbia \\ ${ }^{2}$ University of Niš, Faculty of Medicine, Niš, Serbia \\ ${ }^{3}$ Pediatric Surgery and Orthopedics Clinic, Clinical Center of Nišs, University of Nǐs, Faculty of Medicine, Niš, Serbia
}

\begin{abstract}
We performed a retrospective analysis of all records of children with ingested foreign bodies presented to Clinical Center of Niš Pediatric Clinic and Pediatric Surgery and Orthopedics Clinic in the period from January 2014 to June 2017. The most commonly detected foreign bodies were: metal coins (7) followed by hairclips (2), metal key (1), trichobezoar (1) magnets (1) button battery (1) and zipper puller (1). Regarding anatomical location, foreign bodies were most frequently found in stomach (in 11 patients) followed by esophagus (in 2 patients) and jejunum (in 1 patient). In the majority of our patients (7) foreign bodies passed out of gastrointestinal tract spontaneously. Endoscopic foreign body removal was performed in 5 cases while surgery as a sole therapeutic action was done in 1 patient. In one child multiple magnets were removed from the stomach performing both endoscopic and surgical interventions. Teamwork of a gastroenterologist and a surgeon is crucial for optimizing therapeutic options for each individual patient. Public awareness of this problem and education of parents should be increased to a higher level in order to prevent cases of foreign bodies ingestion in children.
\end{abstract}

Key words: foreign body, endoscopic, removal, surgery, experience.

\section{Introduction}

In most cases (98\%) foreign body (FB) ingestion in children occurs accidentally. The peak incidence is in children between the ages of 5 months and 5 years because during this period, children try to recognize objects from their surroundings by putting them in their mouths. On the other hand, FB ingestion in adolescents is always intentional and raises suspicion of psychiatric illness and substance abuse $[1,2]$. FBs most commonly found in the digestive tract are coins, batteries, magnets and toy parts. Approximately $80 \%-90 \%$ of ingested FBs pass out of the body spontaneously while the rest $10 \%-20 \%$ may require endoscopic intervention or rarely surgery [3]. Children can be asymptomatic or can present symptoms such as the following: dysphagia, vomiting, drooling, refusal of meals, stridor, and respiratory distress. These patients are prone to various complications that range from negligible to life-threatening [4-6].

Correspondence to: Zlatko Djurić, M.D., PhD,

Faculty of Medicine, University of Niš

81 Dr. Zorana Đindića, 18000 Niš, Serbia

Phone: +381641137270

E-mail: zldjuric@yahoo.com

Received July $15^{\text {th }}, 2017$, accepted for publication September $15^{\text {th }}, 2017$

\section{Material and Methods}

The records of all children presented to Clinical Centre of Niš Pediatric Clinic and Pediatric Surgery and Orthopedics Clinic for FB ingestion from January 2014 to June 2017 were evaluated retrospectively. The following data were analyzed: gender and age of patients, presence of symptoms, foreign bodies type, size and location, management, complications and outcome. Radiography of the neck, chest and abdomen were done in order to determine FB location.

Endoscopic FB removal under general anesthesia was the most frequent procedure performed in our patients. Surgical interventions were done in cases when endoscopy was inefficient. All upper digestive endoscopies were done by gastroscope Olympus GIF Q180. Endoscopic tools such as: rat-tooth and alligator graspers, as well as diathermic snare were used in endoscopic FB removal.

\section{Results}

Fourteen patients ( 8 girls, 6 boys) at the age from 8 months to 8 years were found to have FBs in digestive tract. Presenting symptoms were: vomiting (in 2 patients), drooling (in 1 patient) refusal of food (in 1 patient) and dysphagia (in 1 patient), while 9 patients were asymptomatic. In 6 cases parents witnessed FB ingestion in their children. 
The most commonly detected types of FBs were metal coins (7), followed by hairclips (2), metal key (1), trichobezoar (1), magnet (1), button battery (1) and zipper puller (1) (Tab. 1). Regarding anatomical location, FBs were most commonly found in stomach (in 11 patients) and esophagus (in 2 patients) followed by jejunum (in 1 patient). In all patients, except one with trichobezoar, the FB position were determined by radiography.

In 7 children, FBs passed out of digestive tract spontaneously. Endoscopic removal was done in 5 cases. The types of removed FBs were: coins (in 3 cases) and hairclips (in 2 cases). In one patient multiple magnets were removed from stomach performing both endoscopic and surgical interventions. Surgical removal as the sole intervention was done in 1 patient due to gastric trichobezoar.

Mucosal ulcerations and erosions as a consequence of FB impaction were observed in 3 cases (hairclip in the esophagus, hairclip in the stomach, magnets in the stomach). In one patient, (8-month-old girl) during endoscopic removal a long hairclip was stuck in the hypopharynx. The hairclip was successfully pulled out using a pair of Magill forceps.

Table 1 Clinical characteristics of children with gastrointestinal foreign bodies

\begin{tabular}{|c|c|c|c|c|}
\hline Patient's number & Patient's sex and age & FB type & Location & Outcome \\
\hline 1. & $\mathrm{~F}, \quad 8 \mathrm{~m}$ & Hairclip & Esophagus & ER \\
\hline 2. & M, $4 \mathrm{y}$ & Coin & Esophagus & ER \\
\hline 3. & M, $2 \mathrm{y}$ & Coin & Stomach & ER \\
\hline 4. & $\mathrm{~F}, \quad 4 \mathrm{y}$ & Coin & Stomach & ER \\
\hline 5. & F, $\quad 18 \mathrm{~m}$ & Coin & Stomach & PS \\
\hline 6. & M, $22 \mathrm{~m}$ & Coin & Stomach & PS \\
\hline 7. & $\mathrm{~F}, \quad 5 \mathrm{y}$ & Coin & Stomach & PS \\
\hline 8. & M, $3 \mathrm{y}$ & Coin & Stomach & PS \\
\hline 9. & $\mathrm{~F}, \quad 4 \mathrm{y}$ & Magnets & Stomach & $\mathrm{ER}+\mathrm{SR}$ \\
\hline 10. & F, $\quad 5 y$ & Hairclip & Stomach & ER \\
\hline 11. & M, $3 y$ & Zipper puller & Stomach & PS \\
\hline 12. & M, $8 \mathrm{y}$ & Trichobezoar & Stomach & SR \\
\hline 13. & $\mathrm{~F}, \quad 3 \mathrm{y}$ & Metal kee & Stomach & PS \\
\hline 14. & F, $\quad 6 y$ & Button battery & Jejunum & PS \\
\hline
\end{tabular}

F - female, $\mathrm{M}$ - male, $\mathrm{m}$ - months , y - years

FB - foreign body, ER - Endoscopically removed, SR - surgically removed, PS - passed spontaneously

Table 2 Timing of endoscopic intervention in pediatric foreign body ingestions

\begin{tabular}{|c|c|c|c|}
\hline Type & Location & Symptoms & Timing \\
\hline \multirow[t]{4}{*}{ Button battery } & Esophagus & Yes or No & Emergent \\
\hline & Gastric/SB & Yes & Emergent \\
\hline & & No & Urgent (if age $<5$ and $B B \geq 20 \mathrm{~mm}$ ) \\
\hline & & & Elective (if not moving on serial x-ray) \\
\hline \multirow[t]{4}{*}{ Magnets } & Esophagus & Yes & Emergent (if not managing secretions, otherwise urgent) \\
\hline & & No & Urgent \\
\hline & Gastric/SB & Yes & Emergent \\
\hline & & No & Urgent \\
\hline \multirow[t]{4}{*}{ Sharp } & Esophagus & Yes & Emergent (if not managing secretions, otherwise urgent) \\
\hline & & No & Urgent \\
\hline & Gastric/SB & Yes & Emergent (if signs of perforation, then with surgery) \\
\hline & & No & Urgent \\
\hline \multirow[t]{2}{*}{ Food impaction } & Esophagus & Yes & Emergent (if not managing secretions, otherwise urgent) \\
\hline & & No & Urgent \\
\hline \multirow[t]{4}{*}{ Coin } & Esophagus & Yes & Emergent (if not managing secretions, otherwise urgent) \\
\hline & & No & Urgent \\
\hline & Gastric/SB & Yes & Urgent \\
\hline & & No & Elective \\
\hline \multirow[t]{2}{*}{ Long object } & Esophagus & Yes or no & Urgent \\
\hline & Gastric/SB & Yes or no & Urgent \\
\hline \multirow[t]{3}{*}{ Absorptive object } & Esophagus & Yes & Emergent (if not managing secretions, otherwise urgent) \\
\hline & & No & Urgent \\
\hline & Gastric/SB & Yes or no & Urgent \\
\hline
\end{tabular}

BB - button battery; SB - small bowel.

Kramer RE, et al. Management of ingested foreign bodies in children: a clinical report of the NASPGHAN endoscopy committee. J

Pediatr Gastroenterol Nutr 2015; 60: 562-574 


\section{Discussion}

Every child suspected to have ingested a FB should have the frontal and lateral radiography of the head, neck, thorax and abdomen done in order to determine the foreign body kind and location within the digestive tract. It should be kept in mind that plastic and wooden FBs, as well as the animal bones may not be seen in the radiograph. When ingestion of these FBs is suspected upper digestive endoscopy should be done.

Flexibile endoscopy under endotracheal general anesthesia is a method of choice for extraction of FBs from the digestive tract [7]. The rigid endoscopy is an alternative method in cases of sharp FBs presence in the hypopharinx and the proximal esophagus. Endoscopy should be done by a skillful and experienced endoscopist, who should fuse all kinds of endoscopic tools for extraction of FBs, such as: rat-tooth and alligator forceps, polypectomy snare, retrieval net, biopsy forceps, etc. According to the North American Society for Pediatric Gastroenterology, Hepatology and Nutrition endoscopy committee's recently revised guidelines for management of ingested FBs in children, the timing of the FB removal depends on the FB type, location, the presence of symptoms, and the time of the patient's last oral intake and can be: emergent $[<2$ hours from presentation, regardless of nil per os (NPO) status], urgent $[<24$ hours from presentation, following usual NPO guidelines] or elective [ $>24$ hours from presentation, following usual NPO guidelines] (Tab. 2) [7].
Surgery may be one of the alternative methods, particularly in cases when it is not possible to extract the FB by means of endoscopy (trichobezoar, greater number of magnets, sharp foreign bodies inaccessible by endoscopic examination and causing symptomatology) [8]. Magill forceps may be used for extraction of FBs from oropharynx and the upper $1 / 3$ of esophagus $[9,10]$.

All our patients except the one with trichobezoar in his stomach, had the FBs positioned in the digestive tract as determined on radiographs (Fig. 1). The FB most frequently found in the digestive tract, was a metal coin (in 7 cases) (Tab.1). Coins, as most frequently found FBs in the digestive tract, have also been mentioned in studies with a great number of children with ingested foreign bodies [11-13]. From the total number of our 14 patients with ingested FBs, spontaneous elimination of a FBs from gastrointestinal tract occurred in 7 cases. Indication for emergent endoscopic extraction existed in 2 cases: in one patient with a hairclip in esophagus and in one with a coin in the esophagus (Fig. 2a,b).

We have chosen to use endoscopic extraction in 4 cases when FBs were retained in the stomach. In 2 cases it was a metal coin, in 1 a hairclip (Fig. 2c) and in one magnets. We decided to do the endoscopic extraction after the coins had been present in the stomach for more than two weeks and had not passed into more distal parts of gastrointestinal tract.

The radiograph of one patient showed a metal object of unknown origin located in the stomach (Fig.1c). In esophagogastroduodenoscopy the metal object was
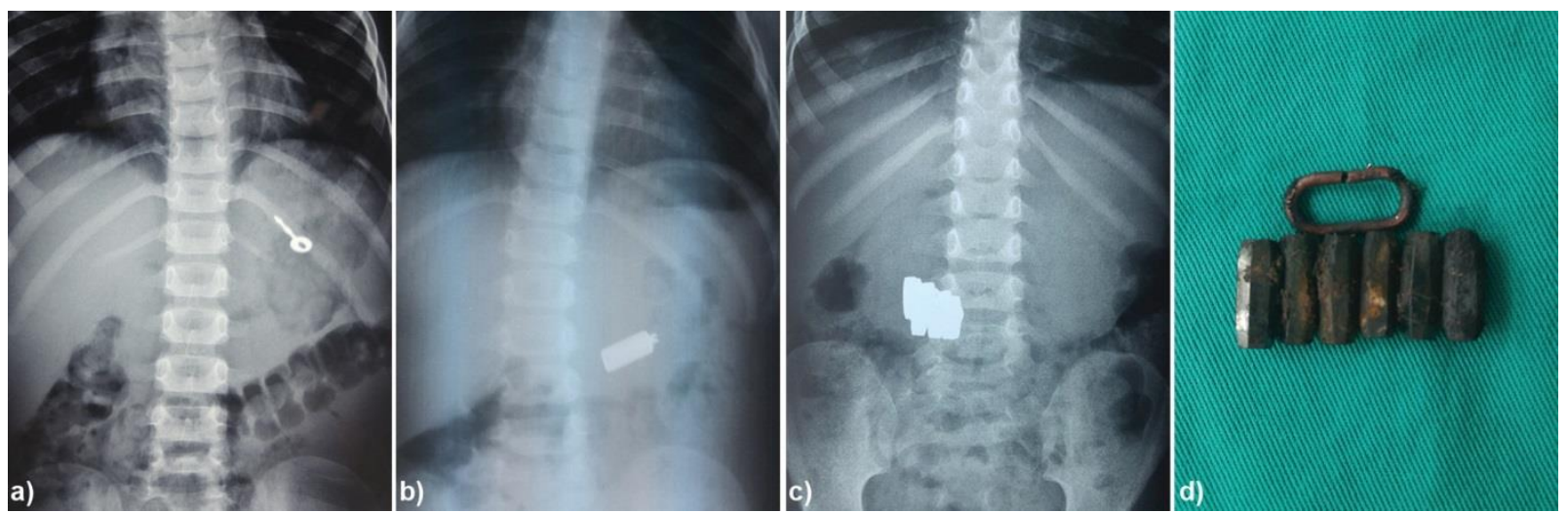

Fig. 1 Gastrointestinal foreign bodies on radiographs and after removal: a) metal key in stomach, b) zipper puller in stomach, c) magnets in stomach, d) magnets and ring after endoscopic and surgical removal
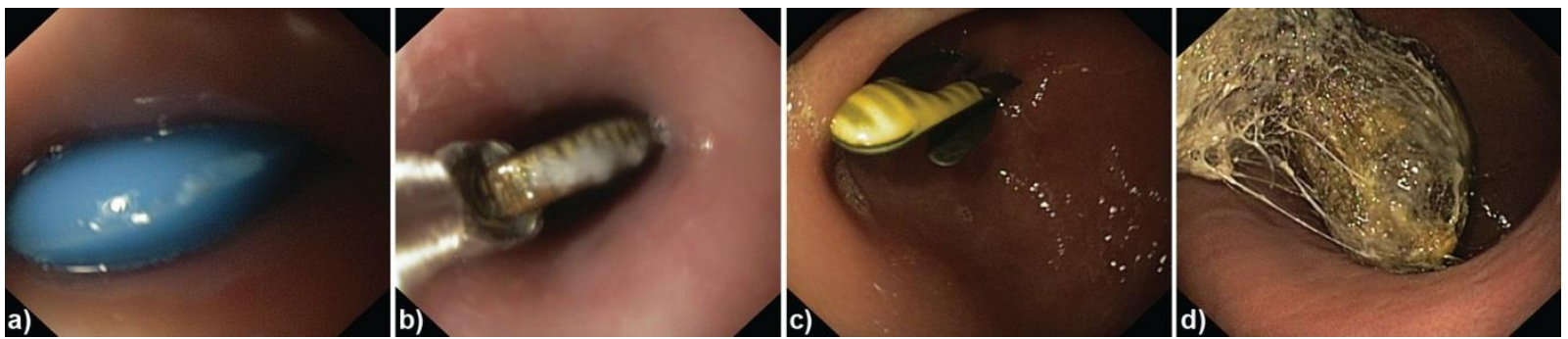

Fig. 2 Endoscopic appearance of gastrointestinal foreign bodies: a) hairclip in esophagus, b) coin in esophagus grasped with rat-tooth forceps, c) hairclip retained in pylorus, d) large gastric trichobezoar 
identified as a group of 6 magnets and 1 ring (probably a part of a toy) which mutually covered the stomach antrum mucosa. Two magnets and the ring were removed by endoscopy with the application of polypectomy snare. The remaining four magnets were removed by surgery (Fig. 1d).

In one of our patients, large trichobezoar (Fig. 2d) was removed from the stomach by surgical intervention. Surgical solution for gastric trichobezoar in children has been mentioned in numerous papers as a method of choice [8,14-16].

Radiograph of one child showed a button battery in the jejunum which fortunately passed the digestive tract without any complications. Button batteries can cause current stream generation that may result in tissue necrosis and perforation [17]. Patients with button batteries in esophagus (regardless of being symptomatic or asymptomatic) and symptomatic patients with button batteries in stomach or small bowel represent a medical emergency [7].

Complications due to the $\mathrm{FB}$ presence in digestive tract may be various: bleeding, perforations, pneumomediastinum, aspiration pneumonia, etc. The appearance of such complications is directly proportional to FB sharpness and the impaction time [18]. Regarding

\section{References}

1. Fatemi HM, Kasius JC, Timmermans A, van Disseldorp J, Fauser BC, Devroey P, et al. Prevalence of unsuspected uterine cavity abnormalities diagnosed by office hysteroscopy prior to in vitro fertilization. Hum Reprod 2010; 25(8):1959-1965.

2. Moini A, Kiani K, Ghaffari F, Hosseini F. Hysteroscopic findings in patients with a history of two implantation failures following in vitro fertilization. Int J Fertil Steril 2012; 6(1):27-30.

3. Bettocchi S, Nappi L, Ceci O, Selvaggi L. Office hysteroscopy. Obstet Gynecol Clin North Am. 2004 Sep;31(3):641-654, xi

4. Pundir J, Pundir V, Omanwa K, Khalaf Y, El-Toukhy T. Hysteroscopy prior to the first IVF cycle: a systematic review and meta-analysis. Reprod Biomed Online 2014; 28(2):151-161.

5. Smit JG, Kasius JC, Eijkemans MJC, Koks CAM, van Golde R, Nap AW, et al. Hysteroscopy before in-vitro fertilisation (inSIGHT): a multicentre, randomised controlled trial. Lancet. 2016 Jun 25;387(10038):2622-9.

6. El-Toukhy T, Campo R, Khalaf Y, Tabanelli C, Gianaroli L, Gordts SS, et al. Hysteroscopy in recurrent in-vitro fertilisation failure (TROPHY): a multicentre, randomised controlled trial. Lancet 2016;387(10038).

7. El-Toukhy T, Campo R, Sunkara SK, Khalaf Y, Coomarasamy A. A multi-centre randomised controlled study of pre-IVF outpatient hysteroscopy in women with recurrent IVF implantation failure: Trial of Outpatient Hysteroscopy [TROPHY] in IVF. Reprod Health 2009; 6: 20.

8. Cenksoy P, Ficicioglu C, Yildırım G, Yesiladali M. Hysteroscopic findings in women with recurrent IVF failures complications arising because of the very presence of the FB in digestive tract, in our group of patients there were asymptomatic lesions of esophagus and stomach mucosa in three patients. In one patient, there was a complication in the course of the FB (hairclip) removal from esophagus. On that occasion, the hairclip got stuck in the hypopharynx and could not be pulled out even after the patient's position changed or by applying various endoscopic maneuvers. Finally, the hairclip was grasped and pulled out by using Magill forceps.

\section{Conclusion}

Our initial experiences in the treatment of gastrointestinal FBs in children confirm without any doubt the significance of the upper digestive endoscopy as a safe and reliable procedure for removing FBs in children. Teamwork of a pediatric gastroenterologist and a surgeon is indispensable in order to respond to all the challenges this problem brings about in pediatric population. Public awareness of this problem and education of parents should be increased to a higher level in order to prevent cases of FBs ingestion in children.

and the effect of correction of hysteroscopic findings on subsequent pregnancy rates. Arch Gynecol Obstet 2013; 287(2):357-360.

9. Kodaman PH. Hysteroscopic polypectomy for women undergoing IVF treatment: when is it necessary? Curr Opin Obstet Gynecol 2016; 28(3):184-190.

10. Madani T, Ghaffari F, Kiani K, Hosseini F. Hysteroscopic polypectomy without cycle cancellation in IVF cycles. Reprod Biomed Online 2009; 18(3):412-415.

11. Tomaževič T, Ban-Frangež H, Virant-Klun I, Verdenik I, Požlep B, Vrtačnik-Bokal E. Septate, subseptate and arcuate uterus decrease pregnancy and live birth rates in IVF/ICSI. Reprod Biomed Online 2010; 21(5):700-705.

12. Bosteels J, Kasius J, Weyers S, Broekmans FJ, Mol BWJ, D'Hooghe TM. Treating suspected uterine cavity abnormalities by hysteroscopy to improve reproductive outcome in women with unexplained infertility or prior to IUI, IVF, or ICSI. Gynecol Surg 2013; 10(3):165-167.

13. Dekel N, Gnainsky Y, Granot I, Racicot K, Mor G. The role of inflammation for a successful implantation. Am J Reprod Immunol 2014; 72(2):141-147.

14. Trninić-Pjević A, Kopitović V, Pop-Trajković S, Bjelica A, Bujas I, Tabs D, et al. [Effect of hysteroscopic examination on the outcome of in vitro fertilization]. Vojnosanit Pregl 2011; 68(6):476-480. 